
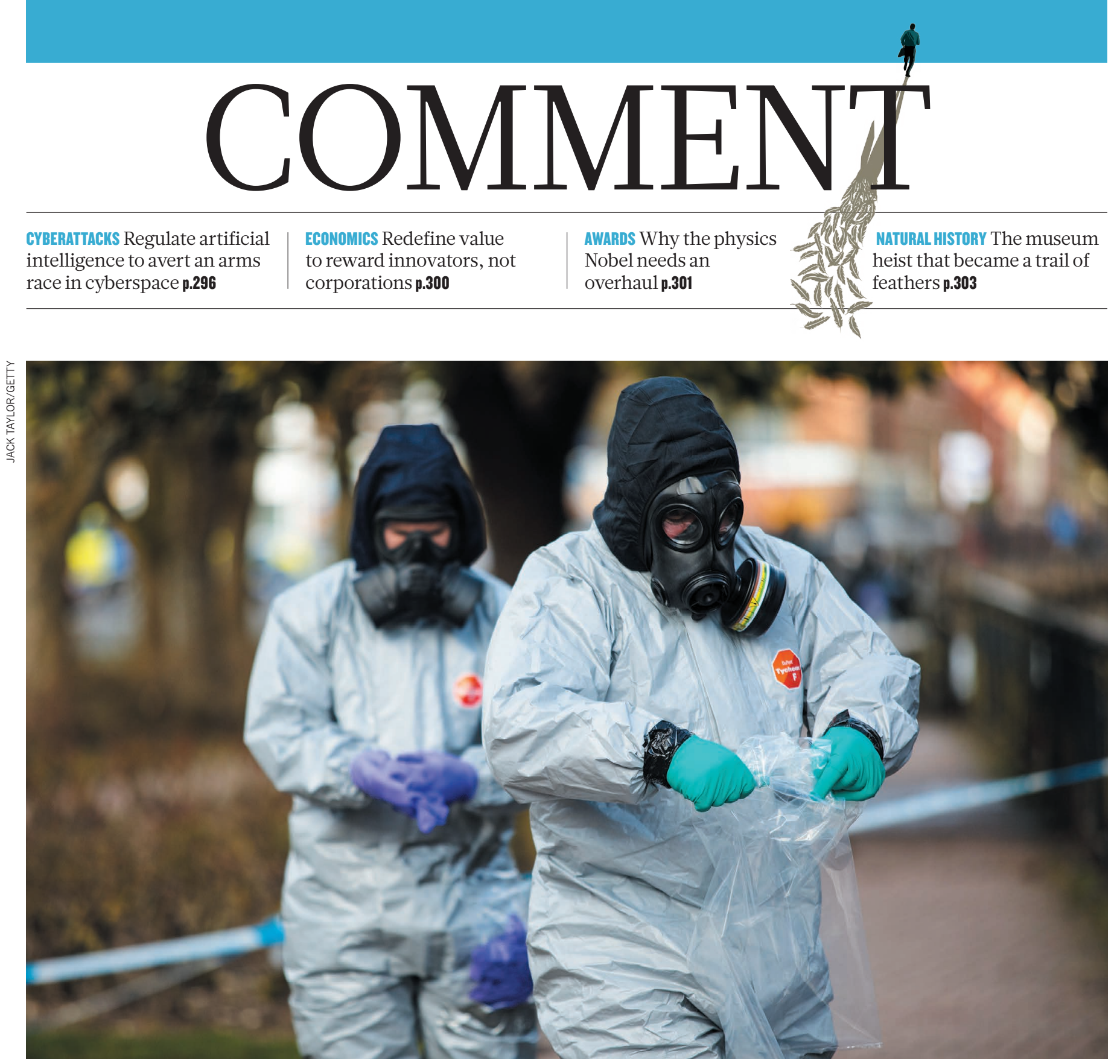

Police collect samples in Salisbury, UK, following the poisoning of Sergei and Yulia Skripal with a nerve agent in March.

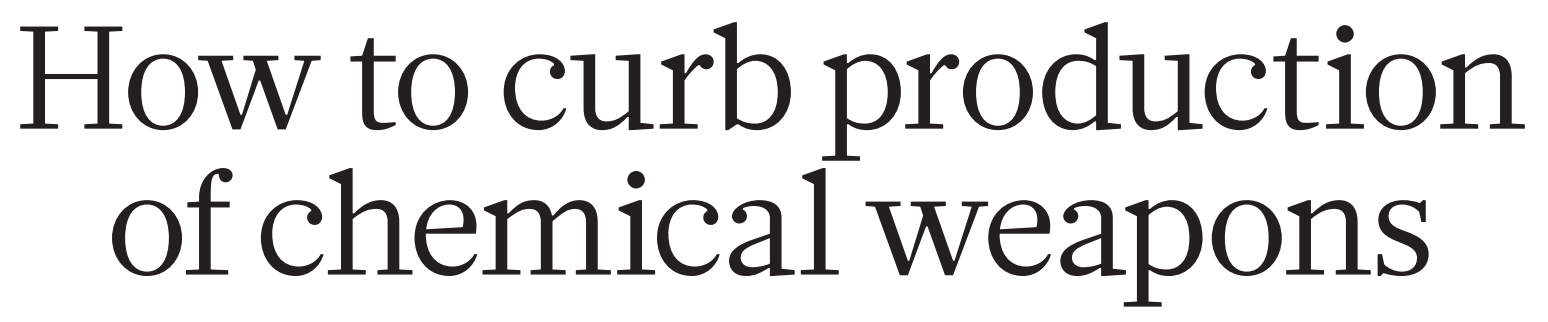

Companies that manufacture and distribute the precursors to lethal agents must be open to surveillance and inspections, argues Leiv K. Sydnes.

\footnotetext{
Tncidents involving chemical weapons are on the rise. In the past week, reports from

Syria allege that scores of people in the city of Douma were killed with a toxic gas, possibly chlorine, a tactic that experts say has been used in Syria at least a dozen times since 2012 (see go.nature.com/2hjzc20). Last month in Salisbury, UK, former Russian intelligence officer Sergei Skripal, his daughter
}

Yulia and a police officer were exposed to an organophosphate called novichok, one of a family of nerve agents said to be the deadliest known ${ }^{1}$. And Kim Jong-nam, the eldest son of former North Korean leader Kim Jong-il, was assassinated in 2017 through exposure to another nerve agent, VX, at Kuala Lumpur international airport in Malaysia.

These recent events risk reversing two decades of progress in disarmament. The intention of the Chemical Weapons Convention $(\mathrm{CWC})^{2}$, finalized in 1992, was to free the world of this weaponry. The Organization for the Prohibition of Chemical Weapons (OPCW), which has implemented the convention since 1997, aimed to destroy all declared stockpiles of chemical weapons within a decade. That hasn't happened, 
but it is still within reach. Today, $96 \%$ of known stockpiles have gone.

It is crucial that, in uncertain times, nations do not fall back on using chemical weapons. In the past few years, political positions and structures that served people well for decades have been questioned. Insecure countries might become more willing to apply chemical weapons to harm opponents and secure strategic advantages.

Meanwhile, the OPCW has lost some of its bite. Although investigators have been allowed in, Syria's breaches have gone unpunished. And neither the United Kingdom nor Malaysia called in experts from the organization right away to deal with their recent nerve-agent attacks, even though immediate assistance is available under the convention.

A new mindset is needed. It is impossible to ban every chemical that could be used to make a weapon, because almost all of them have other applications. For example, chlorine is a common industrial reagent as well as a suffocating gas. More than 60 million tonnes are produced each year and used for purifying water and manufacturing plastics, solvents and pharmaceuticals. Organophosphates are the basis of insecticides and herbicides as well as precursors of nerve agents. Many deadly compounds are easy for any professional chemist to make, with access to the right materials.

There are two solutions: monitor the production and distribution of certain key chemicals (such as organophosphates) that might be misused; and train chemists to be aware of potential security risks.

To realize both, the OPCW should be strengthened and revised. The organization's mandate should be expanded to monitor closely the production of the precursor chemicals used to make the deadliest weapons, especially nerve agents. Its experts must lead all investigations of incidents involving such agents.

Meanwhile, chemists in industry and academia must sign up to a code of conduct surrounding the production, sale and use of chemicals, especially those listed in the CWC. Each time a chemical weapon is used, the reputation of chemists and the chemicals industry is imperilled.

\section{DUAL USES}

Almost any chemical can, in principle, be used as a weapon. Most are inconvenient if the goal is to kill or frighten lots of people quickly. But many can be misappropriated.

Chemical weapons fall broadly into three groups: poisonous commodity chemicals, mustard compounds and nerve agents (see 'Classes of chemical weapon'). Each kills in a different way, by blocking or triggering reactions in the body. The signatures left behind in a person's tissues differ for each weapon and can reveal which compound

was used. Nerve agents are relatively easy to trace, compared to a chlorine attack. They form relatively stable molecular products by linking to biomolecules such as proteins, which can then be sampled in tissue, serum and urine. These products can be converted into other compounds that reveal which agent was used.

The chemical analyses required for such detective work are highly specialized. They demand skilled personnel who know how to prepare the samples and which safety measures and precautions to apply. Detailed measurements must be made with sophisticated instruments, such as gas or liquid

"No one can
usually say
for sure who
launched or
dropped the
shell carrying
the chemical
weapon."
chromatographs and mass spectrometers.

Around two dozen laboratories worldwide are capable of doing this forensic work $^{3,4}$. The OPCW carries out qualitycontrol tests on such labs twice a year and accredits those that pass. Almost all are government facilities that have ties to the military. For example, the Skripal samples were sent to the UK government's Defence Science and Technology Laboratory (DSTL) at Porton Down.

In my view, the OPCW - and no one else - should take charge of all cases involving chemical weapons, in particular suspected nerve agents and mustard compounds. The application of such weapons by any state party to the CWC is an outrageous breach. The implications are so serious and delicate that an impartial, experienced body must resolve the situation. The OPCW is such a body. It should control every step of the process, from the collection and storage of samples to the release of the results. This way, improper interventions will be impossible and the results can be widely trusted.

Regrettably, this procedure was not followed in the Kim and Skripal cases, which remain politically fraught. The Malaysian and UK governments reacted to the incidents on their own, despite the OPCW being able to initiate a rapid response within 24 hours. The UK government officially informed the OPCW secretariat four days after the Skripal incident, asking it to independently verify the novichok structure; the OPCW has now done so and supports the United Kingdom's assessment. I believe that it would have been better to have had international oversight of the samples from the outset.

Another virtue of the OPCW is its sobriety when presenting the results of analyses. It gives only the evidence that proves which agent it has found; it does not speculate as to which party was behind a violation. Such restraint is exercised for good reasons. No one can usually say for sure who launched or dropped the shell carrying the chemical

\section{CLASSES OF CHEMICAL WEAPON Three fatal mechanisms}

Commodity chemicals. Industrial chemicals used as weapons include chlorine $\left(\mathrm{Cl}_{2}\right)$, phosgene $\left(\mathrm{Cl}_{2} \mathrm{C}=0\right)$ and hydrogen cyanide ( $\mathrm{HCN}$ ). Chlorine, a pale green gas heavier than air, suffocates people and destroys the lungs. Its use is hard to prove directly. Samples of the gas must be collected within minutes, before it disperses. Eyewitness interviews and medical records are used instead. The first large-scale use of chlorine in war was on 22 April 1915. The German army released 168 tonnes from 6,000 barrels near Ypres, Belgium. (The chlorine programme's leader was Fritz Haber, who is better known for his work on ammonia synthesis.)

Mustard compounds. These organic compounds contain sulfur or nitrogen groups (such as bis(2-chloroethyl) sulfide $\left.\left(\mathrm{ClCH}_{2} \mathrm{CH}_{2} \mathrm{SCH}_{2} \mathrm{CH}_{2} \mathrm{Cl}\right)\right)$ that react with skin and the airways. Mustard gas, a colourless liquid that boils at $217^{\circ} \mathrm{C}$, has been used in warfare since 1917 and causes swelling and blisters. The type of agent used can be determined by the presence of stable biomarkers in biopsy samples. A mustard compound was used during the Iran-Iraq war in Halabja in the Kurdistan autonomous region of Iraq on 16 March 1988: 5,000 people died immediately and many more were injured.

Nerve agents. These phosphorbased organic compounds affect the transmission of signals across nerve junctions. They inhibit the enzyme acetylcholinesterase, and so increase the amount of one type of nerve signal that reaches muscles, causing paralysis. The agents are colourless liquids that can kill within a minute. People exposed convulse and foam at the mouth, then their respiratory system and heart muscles fail. Molecules indicating which agent was used can be collected from tissues. One example is the release of sarin on the Tokyo subway in 1995 by a cult group, in which 12 people were killed. L.K.S. 


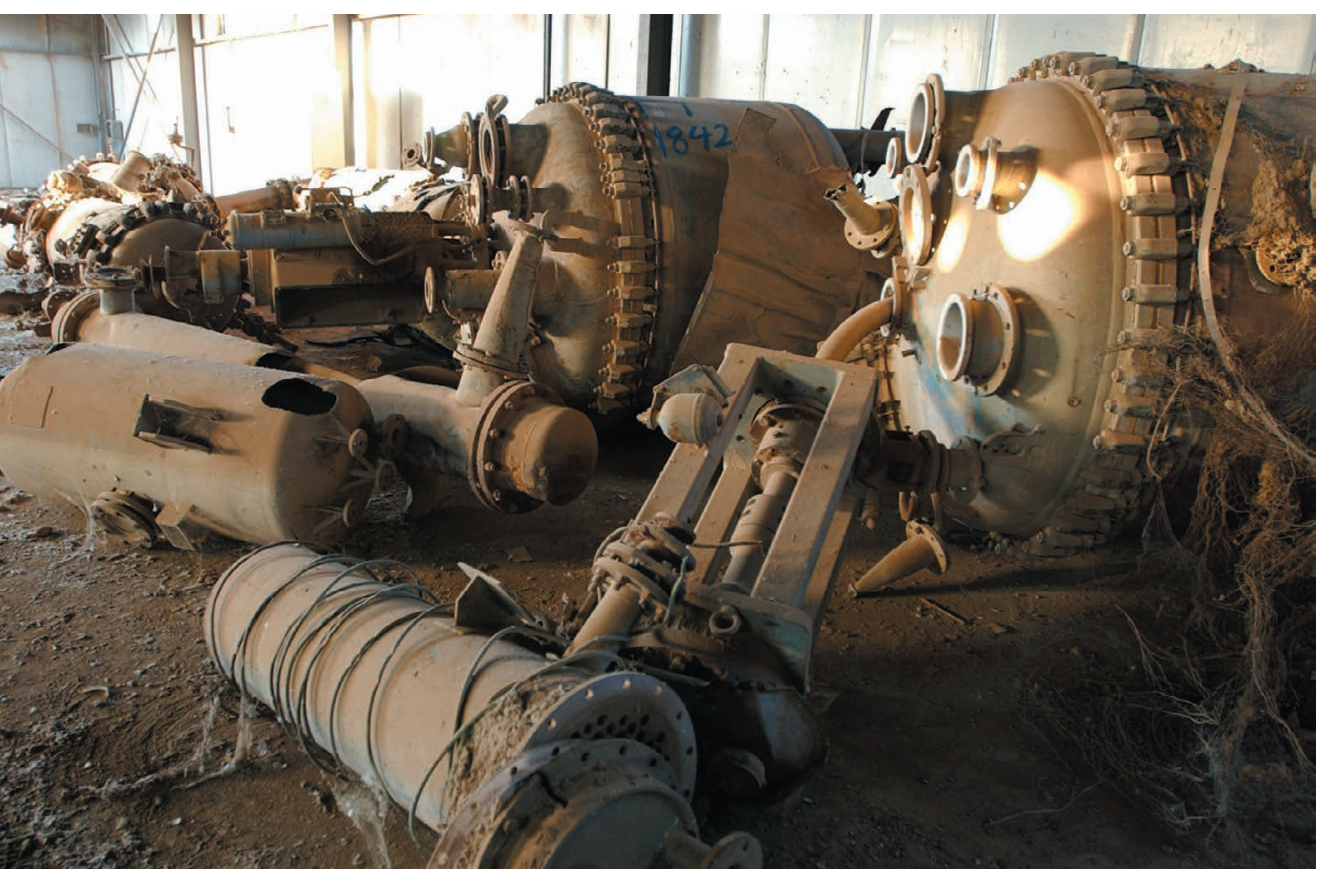

Disabled fermentation vats and equipment at the Muthanna chemical-weapons factory in Iraq.

(all sides would deny it). And it is impossible to tell where an agent was produced without also having samples from that same location with which to match it. With no comparison samples, it is like trying to identify a person from only a fingerprint without access to a database of prints.

In the UK novichok case, as far as I know, the precursors and the reagents used to prepare this nerve agent are unavailable to cross-check. If that is so, then the origin of that weapon could not be established on the basis of the chemistry alone - other evidence or intelligence would be needed to determine the chemical's source. Gary Aitkenhead, chief executive of the DSTL, clarified this point a month after the incident.

Nor does the fact that Russian chemists first developed novichok compounds indicate definitively where this material came from. Information about novichok nerve agents has been available in the literature for years $^{5-7}$. In theory, it is not technically difficult to synthesize novichok compounds, although some are harder to make than others. The difficulties lie in obtaining the necessary precursors and reagents, and safely preparing the agent without self-exposure.

\section{PREVENT PROLIFERATION}

To reiterate, we need to do two things to limit chemical weapons: control the ingredients and improve ethical standards in the chemical profession.

Banning chemicals is impossible because almost all the relevant chemicals required for making chemical weapons have good uses as well as bad. For example, isopropyl alcohol (IPA) is widely used as a solvent; millions of tonnes are used each year in the production of a range of products, including household cleaners, pesticides and personal-care products. Yet react IPA with methylphosphonyl difluoride, and you produce the nerve agent sarin.

The focus, therefore, must be on tightening security around particular commercial chemicals. The priority should be surveillance and inspection of the producers and distributors of the relatively few phosphorus compounds that can be used to make nerve agents (including the five groups of precursors and seven specific precursors listed in the CWC). The OPCW must be in charge of this inspectorate, because it would require the backing of state parties to the CWC.

Meanwhile, the chemistry community in both academia and industry - needs to become more aware of the potential misuse of certain chemicals. For example, in the 1990 s, a colleague of mine inspected the main Iraqi facility that produced chemical weapons in the 1980s - the Muthanna State Establishment, northwest of Baghdad. To his disbelief, he discovered 4,000 tonnes of weapons ready to be launched (mainly mustard gas and cyclosarin), as well as 20,000 tonnes of precursor chemicals for making them. Storerooms were filled with barrels of thionyl chloride - an industrial chemical listed under the CWC as having possible weapons uses. Many of these were bought from European companies ${ }^{8}$. Presumably no red flags were raised among company staff when the sizes of the Iraqi orders went from kilograms to tonnes.

In my experience, few chemists know which chemicals to pay attention to from a weapons perspective. Most have never heard of the three lists of precursors and toxic chemicals (schedules 1-3) in the CWC, even if they are aware of the convention itself. Hardly any universities incorporate weapons-related topics in curricula for chemists and chemical engineers. This has to change. And here the OPCW can assist, through ethical guidance and educational material.

In 2015, after a lengthy process, the OPCW took a leap by publishing The Hague Ethical Guidelines for chemistry professionals (see go.nature.com/2epdgrj). It also set up an Advisory Board on Education and Outreach, which has begun to post educational materials online (see go.nature. com/2jnzmp9). So far, it has had little impact. More needs to be done to spread the word.

\section{EXPAND MANDATE}

To stop renewed proliferation, the OPCW's powers, roles and influence should be expanded, so that it can act more quickly and forcefully when the CWC is breached or other threats arise. State parties to the convention should enable the OPCW to become more heavily involved in awareness-raising, inspections, outreach and surveillance. And the permanent delegations to the OPCW should contact universities and professional organizations in their countries to highlight these important issues among chemists and within the chemical industry.

Research chemists, especially in universities, should work to raise awareness of the chemical challenges related to the CWC. A first step would be to make the convention mandatory reading for all chemistry students. Second, OPCW educational material should be used in university courses. Third, The Hague Ethical Guidelines should be used to improve the ethical framework of the chemical profession.

Leiv K. Sydnes is professor of chemistry at the University of Bergen, Norway. He chaired the international task group that assessed the impact of scientific advances on the Chemical Weapons Convention in 2007 and 2012.

e-mail:leiv.sydnes@uib.no

1. Malygin, V. V., Sokolov, V. B., Richardson, R. J. \& Makahaeva, G. F. J. Toxicol. Environ. Health A 66, 611-625 (2003).

2. Organisation for the Prohibition of Chemical Weapons (OPCW). Convention on the Prohibition of the Development, Production, Stockpiling and Use of Chemical Weapons and on their Destruction (OPCW, 2005).

3. OPCW Technical Secretariat. Status of the Laboratories Designated for the Analysis of Authentic Biomedical Samples (OPCW, 2017).

4. OPCW Technical Secretariat. Status of the Laboratories Designated for the Analysis of Authentic Environmental Samples (OPCW, 2017).

5. Hoenig, S. L. Compendium of Chemical Warfare Agents (Springer, 2007).

6. Kruglyak, Y. L., Malekin, S. I. \& Martynov, I. V. Zh. Obs. Khim. 42, 811-814 (1972).

7. Raevskii, O. A. et al. Zh. Obs. Khim. 57, 2073-2078 (1987).

8. Pearson, G. S. The Search for Iraq's Weapons of Mass Destruction: Inspection, Verification and Non-Proliferation (Palgrave/Macmillan, 2005). 